\title{
Assessment of Patients Satisfaction towards Nursing Care in Mosul City
}

\section{Hospitals}

\author{
Basher Mohamed Bunyan * \\ Salah MS Hassan **
}

\begin{abstract}
Background and aim: Patients' satisfaction has been used as a significant indicator of quality services provided by health care personnel. Consequently, the most important predictor of patients, overall satisfaction with hospital care is particularly related to their satisfaction with nursing care. Because nurses comprise the majority of health care providers. The aim of the current study is to assess the patients' satisfaction toward nursing care provided in medical and surgical units in Mosul city hospitals.

Materials and method: A descriptive study represented in a purposive sample consisted of 1000 patients, the study was carried out at three different hospitals include Ibn Sina, Al Jumhory and Al Salam teaching hospitals. The study was conducted at medical and surgical Units; the data were collected through the use of constructing a questionnaire which consists of two parts, demographic characteristics and patients' satisfaction toward nursing care. Content validity was determined by presenting the questionnaire to a panel of 17 experts. The data were analyzed through the application of descriptive statisticas and inferential statistical analysis.

Results: Results of the current study revealed that more than half of patients were male 569(56.9\%). The most of patients was married 785(78.5\%). The majority of patients were from rural 562(56.2\%), additionally, the male more satisfied than female and surgical patients' satisfaction more than medical patients. the old age satisfaction more than another age groups, such as the lower level education high satisfied, the married patients more satisfied from other, the unemployed patients more satisfaction, the patients had not previous hospitalization more satisfaction. The patients are more satisfaction toward nursing skills from other domains. While there were a statistical significant difference between patient satisfaction toward nursing care provided and patients characteristics.
\end{abstract}

Conclusion: The current study concluded that patients were satisfied to nursing care

Recommendation: the study recommended that further studies should be conducted concerning patients satisfaction with nursing care provided in all hospitals.

Keywords: Patients satisfaction, Assessment, Nursing care.

\section{INTRODUCTION}

Patient satisfaction has been used as an indicator of quality services provided by health care personnel, the most important predictor of patient's overall satisfaction with hospital care is particularly related to their satisfaction with nursing care (Al Qahtani and Al Dahi, 2015). patients' satisfaction with nursing care is an important component for all health care professionals (Kuosmanen, 2006).

The first study of patient satisfaction in nursing occurred in 1956. Assessment of the patient so satisfying is viewed by the authors as vital and necessary in modern health care due to rising costs and the need for resourcefulness and efficiency of health care delivered by health institutions. Patient satisfaction is viewed as a significant and valid measure of efficiency in health care delivery. Patients are often active and usually capable of forming opinions regarding care received.
Patient satisfaction has gained the attention from global scholars. Researches in the developed countries such as United States (US), United Kingdom (UK) and Canada have pointed out the importance of patients' satisfaction as the core quality indicator, particularly in the area of nursing care. Nurses are the frontline people that patients most likely meet up with, spend the highest amount of time with and rely upon for recovery during their hospitalization. Nursing care plays a prominent role in determining the overall satisfaction of patients' hospitalization experience (Wagner and Bear, 2009).

Patient satisfaction is defined as the extent of the resemblance between the expected quality of care and the actual received care. Patient satisfaction with nursing care is important for any health care agency because nurses comprise the majority of health care providers and they provide care for patients 24 hours a day (Mohsen, 2004).

Assessing patient satisfaction with nursing

* MSc Candidate / Salahudeen Health Directorate.

** Assistant Professor/College of Nursing / University of Kirkuk. 
care is important in evaluating whether patients' needs are fulfilled and subsequently facilitating in the planning as well as implementing appropriate nursing interventions for patients. Determining factors contribute most to patient satisfaction can further assist nurses in improving the quality of nursing care. Hence, patient satisfaction with nursing care is an imperative determinant of quality of care particularly in the clinical/ healthcare facility settings (Laschinger et. al., 2006).

Nursing services is one of the most important components of hospital services which has two major objectives; nursing care of sick patients and prevention of disease and promotion of health. Nurses form a very important group, which is the largest single technical group of personal engaged in hospital care next to doctors and consume almost one third of hospital cost. A hospital may be soundly organized, beautifully situated and well equipped, but if the nursing care is not of high quality, the hospital will fail in its responsibility of providing care (Brain et. al., 2002).

\section{MATERIALS AND METHOD}

A descriptive study was adopted to achieve the objectives of the present study for the period from $1^{\text {st }}$ October 2013 till the $30^{\text {th }}$ of March 2016. The data were collected from Mosul city which is the second most important city in Iraq. It is located in the Northwest region of Iraq. The study was carried out in medical and surgical wards in Ibn Sena teaching hospital, Al-Salam teaching hospital and Al-Jumhory teaching hospital. Purposive sampling (1000) patients participated in this study; data were collected by questionnaire and interview techniques.

\section{RESULTS}

Table (1):Demographic Characteristics of the Study Samples.

\begin{tabular}{|c|c|c|c|}
\hline \multicolumn{2}{|c|}{ Variables } & No. & $\%$ \\
\hline \multirow{3}{*}{ Gender } & Male & 569 & 56.9 \\
\hline & Female & 431 & 43.1 \\
\hline & Total & 1000 & $100 \%$ \\
\hline \multirow{7}{*}{ Age } & $18-27$ & 163 & 16.3 \\
\hline & $28-37$ & 180 & 18.0 \\
\hline & $38-47$ & 233 & 23.3 \\
\hline & $48-57$ & 242 & 24.2 \\
\hline & 58-more than & 182 & 18.2 \\
\hline & $M \pm S D$ & \multicolumn{2}{|c|}{$43.04 \pm 15.96$} \\
\hline & Total & 1000 & $100 \%$ \\
\hline \multirow{3}{*}{ Residence } & Urban & 438 & 43.8 \\
\hline & Rural & 562 & 56.2 \\
\hline & Total & 1000 & $100 \%$ \\
\hline \multirow{4}{*}{ Social status } & Single & 98 & 9.8 \\
\hline & Married & 785 & 78.5 \\
\hline & Widow & 69 & 6.9 \\
\hline & Divorced & 48 & 4.8 \\
\hline \multirow{6}{*}{ Educational levels } & read and write & 201 & 20.1 \\
\hline & Primary school & 338 & 33.8 \\
\hline & Intermediate school & 322 & 32.2 \\
\hline & Secondary school & 76 & 7.6 \\
\hline & College or Institution & 63 & 6.3 \\
\hline & Total & 1000 & $100 \%$ \\
\hline \multirow{6}{*}{ Occupational status } & Employed & 229 & 22.9 \\
\hline & Unemployed & 224 & 22.4 \\
\hline & retired & 181 & 18.1 \\
\hline & Housewife & 288 & 28.8 \\
\hline & Another work & 78 & 7.8 \\
\hline & Total & 1000 & $100 \%$ \\
\hline Previous admission & $1^{\text {st }}$. time & 242 & 24.2 \\
\hline
\end{tabular}




\begin{tabular}{||c|c|c|c|}
\hline \hline \multirow{4}{*}{ Type of disease } & $2^{\text {nd }}$. Time & 326 & 32.6 \\
\cline { 2 - 4 } & $3^{\text {rd }}$.time and more. & 432 & 43.2 \\
\cline { 2 - 4 } & Total & 1000 & $100 \%$ \\
\hline \multirow{3}{*}{ Type of admission } & Chronic & 488 & 48.8 \\
\cline { 2 - 4 } & Acute & 512 & 51.2 \\
\cline { 2 - 4 } & Total & 1000 & $100 \%$ \\
\cline { 2 - 4 } & Emergency & 535 & 53.5 \\
\cline { 2 - 4 } & Non-emergency & 465 & 46.5 \\
\hline \multirow{3}{*}{ Wards } & Total & 1000 & $100 \%$ \\
\cline { 2 - 4 } & Medical & 500 & 50.0 \\
\cline { 2 - 4 } & Surgical & 500 & 50.0 \\
\hline
\end{tabular}

Table (2): Client's Responses to Satisfaction items Within 5- Level Scale by Total Frequencies and Percentages.

\begin{tabular}{|c|c|c|c|c|c|}
\hline \multirow{2}{*}{ Variables } & communication & skills & Environment & Information & \multirow{2}{*}{ GMS } \\
\hline & MS. & MS. & MS. & MS. & \\
\hline \multicolumn{6}{|l|}{ Gender } \\
\hline Male & 3.56 & 3.99 & 3.85 & 4.02 & 3.84 \\
\hline Female & 3.73 & 4.02 & 3.82 & 3.66 & 3.8 \\
\hline \multicolumn{6}{|l|}{ Age } \\
\hline $18-27$ & 3.58 & 4.09 & 3.87 & 3.71 & 3.81 \\
\hline $28-37$ & 3.8 & 4.21 & 3.79 & 3.74 & 3.9 \\
\hline $38-47$ & 3.69 & 4.13 & 3.71 & 4.02 & 3.88 \\
\hline $48-57$ & 3.61 & 4.11 & 3.78 & 4.1 & 3.88 \\
\hline 58-more & 3.76 & 4.2 & 3.9 & 4.06 & 3.99 \\
\hline \multicolumn{6}{|l|}{ educational level } \\
\hline Write and read & 4.07 & 4.1 & 3.83 & 3.78 & 3.9 \\
\hline Primary & 3.74 & 4.2 & 3.82 & 3.78 & 3.95 \\
\hline Intermediate & 3.76 & 4.18 & 3.86 & 4 & 3.91 \\
\hline Secondary & 3.73 & 4.21 & 3.8 & 4.06 & 3.9 \\
\hline collage & 3.65 & 3.93 & 3.9 & 4.02 & 3.86 \\
\hline \multicolumn{6}{|l|}{ Social status } \\
\hline Single & 3.53 & 4.11 & 3.74 & 3.76 & 3.79 \\
\hline Married & 3.75 & 4.16 & 3.84 & 3.96 & 3.93 \\
\hline Divorced & 3.72 & 4.23 & 3.8 & 3.76 & 3.89 \\
\hline widow & 3.6 & 4.05 & 3.98 & 3.91 & 3.87 \\
\hline \multicolumn{6}{|l|}{ Occupational } \\
\hline Employed & 3.74 & 4.21 & 3.91 & 3.85 & 393 \\
\hline Unemployed & 3.93 & 4.17 & 3.94 & 4.18 & 4.05 \\
\hline Self employed & 3.74 & 4.19 & 3.8 & 3.73 & 3.88 \\
\hline Housewife & 3.63 & 4.07 & 3.79 & 3.65 & 3.79 \\
\hline Retired & 3.56 & 4.06 & 3.74 & 4.09 & 3.85 \\
\hline \multicolumn{6}{|l|}{ Admission } \\
\hline Emergency & 3.74 & 4.18 & 3.89 & 3.91 & 3.93 \\
\hline Nonemergency & 3.69 & 4.12 & 3.77 & 3.95 & 3.88 \\
\hline \multicolumn{6}{|l|}{ Previous admission } \\
\hline $1^{\text {st }}$.time & 3.74 & 4.12 & 3.92 & 4.04 & 3.94 \\
\hline $2^{\text {nd }}$.time & 3.7 & 4.21 & 3.8 & 3.9 & 3.9 \\
\hline $3^{\text {rd }}$ time and more & 3.72 & 4.14 & 3.81 & 3.8 & 3.89 \\
\hline \multicolumn{6}{|l|}{ Department } \\
\hline Surgical & 3.7 & 4.12 & 3.95 & 4.12 & 3.95 \\
\hline Medical & 3.73 & 4.13 & 3.71 & 3.83 & 3.86 \\
\hline
\end{tabular}

MS = Mean score. GMS = Grand mean score. 
Table (3): Comparison of the Patients Satisfaction Domains Regarding to Their Gender.

\begin{tabular}{|c|c|c|c|c|c|c|}
\hline Categories & Gender & No. & $\overline{\mathbf{X}}$ & $\begin{array}{l}\text { S.D } \\
\end{array}$ & T.obs & $\mathrm{P} \leq 0.05$ \\
\hline \multirow{2}{*}{ Nurses Communication } & Male & 569 & 55.59 & 7.08 & \multirow{2}{*}{1.31} & \multirow{2}{*}{ NS } \\
\hline & Female & 431 & 56.17 & 6.68 & & \\
\hline \multirow{2}{*}{ Nurses Skills } & Male & 569 & 57.99 & 7.35 & \multirow{2}{*}{1.26} & \multirow{2}{*}{ NS } \\
\hline & Female & 431 & 58.57 & 7.03 & & \\
\hline \multirow{2}{*}{ Nurses Environment } & Male & 569 & 42.28 & 6.43 & \multirow{2}{*}{0.56} & \multirow{2}{*}{ NS } \\
\hline & Female & 431 & 42.04 & 6.88 & & \\
\hline \multirow{2}{*}{ Nurses Information Provided } & Male & 569 & 41.11 & 6.94 & \multirow{2}{*}{7.84} & \multirow[b]{2}{*}{$\mathrm{S}$} \\
\hline & Female & 431 & 36.9 & 10.01 & & \\
\hline
\end{tabular}

$t$ critical $=1.96 \quad \mathrm{DF}=998$ NO. $=$ Number. $\mathrm{X}=$ Mean score. SD. $=$ Stander deviation.

Table (4): Comparison of the Patients Satisfaction Domains Regarding to Residence.

\begin{tabular}{|c|c|c|c|c|c|c|}
\hline Categories & Residence & No. & $\mathbf{X}$ & S.D & T.obs & $\mathrm{P} \leq 0.05$ \\
\hline \multirow{2}{*}{ Nurses Communication } & Urban & 438 & 55.06 & 7.44 & \multirow{2}{*}{2.47} & \multirow{2}{*}{ S } \\
\hline & Rural & 562 & 56.14 & 6.24 & & \\
\hline \multirow{2}{*}{ Nurses Skills } & Urban & 438 & 57.60 & 7.27 & \multirow[t]{2}{*}{2.39} & \multirow{2}{*}{$\mathrm{S}$} \\
\hline & Rural & 562 & 58.71 & 7.08 & & \\
\hline \multirow{2}{*}{ Nurses Environment } & Urban & 438 & 41.51 & 6.96 & \multirow{2}{*}{2.41} & \multirow{2}{*}{$\mathrm{S}$} \\
\hline & Rural & 562 & 42.53 & 6.29 & & \\
\hline \multirow{2}{*}{ Nurses Information Provided } & Urban & 438 & 39.62 & 7.85 & \multirow{2}{*}{1.31} & \multirow{2}{*}{ NS } \\
\hline & Rural & 562 & 38.89 & 9.20 & & \\
\hline
\end{tabular}

$t$ critical $=1.96 . \quad \mathrm{DF}=998 . \mathrm{SD}=$ Stander deviation. $\mathrm{S}=$ Significant $. \mathrm{NS}=$ No significant. No $=$ Number.

Table (5): One-way Analysis of Variance for the Difference Between Patients Satisfaction Domains and Their Age.

\begin{tabular}{|c|c|c|c|c|}
\hline Categories & S.O.V & S S & $\overline{M ~ S ~}$ & $\begin{array}{l}\text { F.Obs } \\
\end{array}$ \\
\hline \multirow{3}{*}{ Nurses Communication } & Between Groups & 1050.73 & 262.68 & \multirow{3}{*}{$\begin{array}{c}5.59 \\
\mathrm{~S}\end{array}$} \\
\hline & Within Groups & 46756.30 & 46.99 & \\
\hline & Total & 47807.03 & & \\
\hline \multirow{3}{*}{ Nurses Skills } & Between Groups & 132.12 & 33.03 & \multirow{3}{*}{$\begin{array}{l}0.63 \\
\text { NS }\end{array}$} \\
\hline & Within Groups & 51941.87 & 52.20 & \\
\hline & Total & 52073.99 & & \\
\hline \multirow{3}{*}{ Nurses Environment } & Between Groups & 867.19 & 216.79 & \multirow{3}{*}{$\begin{array}{c}5.01 \\
S\end{array}$} \\
\hline & Within Groups & 43006.95 & 43.22 & \\
\hline & Total & 43874.14 & & \\
\hline \multirow{3}{*}{$\begin{array}{c}\text { Nurses Information } \\
\text { Provided }\end{array}$} & Between Groups & 2881.63 & 720.40 & \multirow{3}{*}{$\begin{array}{c}9.95 \\
\text { S }\end{array}$} \\
\hline & Within Groups & 71987.15 & 7234 & \\
\hline & Total & 74868.79 & 12.34 & \\
\hline
\end{tabular}

$\mathrm{F}$ critical $=2.21 \quad \mathrm{DF}=999 . \mathrm{S}=$ Significant. $\mathrm{NS}=$ No significant. S.O.V $=$ Statement of variance. $\mathrm{SS}=$ sum square. $\mathrm{MS}=$ mean score.

\section{DISCUSSION}

\section{Part I: Discussion patients demographic} characteristics.

Analysis of the results of patients demographic characteristics indicated that the $596(56.9 \%)$ of them were male and 431 (43.1\%) were female. Our study results is in agreement with Al Qahtani and Al Dahi (2015) founded the male $246(59.4 \%)$ and female 186
(40.6\%). Additionally, another study which submitted by Soufi et. al. (2010) show that patients respondents $(53.7 \%)$ were male and $(46.3 \%)$ were female .Analysis of the results indicated that the male more satisfied than female. The results is in agreement with study donated by Al Qahtani and Al Dahi (2015) and Ahmad and Alasad (2004) founded the male more satisfied than female. According to the age 
Analysis of the results of present study indicated that is common age group between (48 -57) years and constituted $242(24.2 \%)$ of the total sample and the Mean \pm standard deviation of age was $(43.04 \pm 15.69)$ years. Shnishil and Mansour (2013) founded the more age group (51-60) years and constituted37 $(24.66 \%)$ and the Mean \pm standard deviation of age was (45.3 \pm 14.2) years. Al-Assaf (2009) founded the Mean \pm standard deviation of age from the participants was $(44.09 \pm 14.87)$ years.

Analysis of the results of present study indicated that patients with age group (58- more) most satisfied from others. This result is in agreement with El Awa et. al. (2010) who reported that older patients are generally more satisfied than younger patients. This may be attributed to that patients at age fifteen years were at the stage of adolescent that is characterized by different reactions toward hospitalization and the role that the illness may play in their life depending on the quality of the support systems available to them, in addition to physical changes related to the transition from childhood to maturity and disease process may be responsible for psychological instability that reflects their dissatisfaction.

The educational level of the patients participants in the present study analysis indicated that the $338(33.8 \%)$ of them were have Primary school. Shnishil and Mansour (2013) founded the more of educational level was primary school 37(24.7\%). Ziaei (2011) reported that was the Primary school is about $125(27.2 \%)$, the results of present study also denoted that the lower levels of education had higher levels of satisfaction. Such findings were consistent with findings of Alasad and Ahmad (2003); Fleischer et. al. (2009) found that patients with higher levels of education had lower levels of satisfaction with nursing care .

The results of present study also denoted that the majority of participant were married and constitute $785(78.5 \%)$ of the total sample. Tang et al. $(2013)^{15}$. reported the $(66 \%)$ from the sample was married. Soufi et. al. (2010) founded that was $148(69.2 \%)$ of the sample married.

\section{Part II: Discussion Patients Satisfaction toward Nursing Care Domains}

Communication domain data analyses show that satisfaction of patients with nurses' communication was higher (3.7). Our results of my study is in agreement with the study presented by Abdel Maqsood and other (2012)(16) El-Nagger et. al. (2013). Nurses skills domain data analyses show that satisfaction of patients with Nurses skills was high scoring (4.1). This result of study is in agreement with the study donated by Abdel Maqsood et. al. (2012). Nurses environment domain data analyses show that satisfaction of patients with nurses environment was high scoring (3.8). This result of study is in agreement with the study donated by Papastavrou et. al. (2014). Nurses information provided domain data analysis show that satisfaction of patients with Nurses information provided was (3.9). This result of study is in agreement with the study donated by Azizi-Fini et. al. (2012).

\section{CONCLUSION}

The current study concluded that patients were satisfied regarding nursing care provided in Abn sina, Al jumhory and Al salam Teaching Hospitals in the Mosul. The surgical wards patients in this study reported high level of satisfaction with the nursing care they received. Professional-technical competencies was found to be contributed highest towards their satisfaction and followed by Information provided. Information provided appeared to be an area requires further improvement in order to enhance patients satisfaction particularly in the medical wards setting of this hospital.The aspect of patients satisfaction is indeed a very essential determinant of nursing service quality. Nursing administrators and nurses can utilize the findings to recognize the strengths and weaknesses of nursing services and adopt necessary measures in enhancing quality of nursing care in order to increase patient satisfaction.

\section{RECOMMENDATIONS}

The study concluded that nursing curriculums should give attention for developing the communication skills and information provided of their students side by side with other skills and also nurses should practice these skills in their working places. Further studies should be conducted concerning patients satisfaction with nursing care provided in all hospitals. Replication of the study in a different location with a larger sample could provide reliability as well as validity to the findings of this study. Furthermore, recommendation for further research would also to include the use of qualitative approach to explore the patients' perception of satisfaction and meaning of 'quality care'.

\section{REFERENCES}

Abdel Maqsood A, Oweis A, and Hasna F. Differences between patient's expectations 
and satisfaction with nursing care in a private hospital in Jordan. International Journal of Nursing Practice. 2012; 18: Pp. 140-146.

Ahmad M and Alasad J. Predictors of patients' experiences of nursing care in medicalsurgical wards. International Journal of Nursing Practice. 2004; 10(9):Pp. 235241.

Al assaf N. (2009). Factors Related to Patient Satisfaction with Hospital Health Care. Iraqi J. Comm. Med. 4. P.p. 218-223.

Al asad J and Ahmad M. (2003). Patient's satisfaction with nursing care in Jordan. International Journal of Health Care Quality Assurance. 16(6). P.p. 279-285.

Al Qahtani, M.; and Al Dahi, S. (2015). Satisfaction with nursing care from the inpatients' perspective in Prince Salman Armed Forced Hospital Tabuk, Saudi Arabia. Middle East Journal of Family Medicine. 2(13). P.p. 14-16.

Azizi-Fini, I.; Mousavi, M.; Mazroui-Sabdani, A.; Adib-Hajbaghery, M. (2012). Correlation Between Nurses Caring Behaviors and Patients' Satisfaction. Nurs Midwifery Stud. 1(1).Pp.36-40.

Brain, S.; Empereur, F.; and Guillemain, F. (2002). Factors determining inpatient satisfaction with care. Social Sci. Med. 54. P.p. 493-504

El Awa, B.; Habib, S.; and El Deek, M. (2010). The Impact of Accreditation on Patient Safety and Quality of Care as Perceived by Nursing Staff in a University Hospital in Saudi Arabia. Research Journal of Medical Sciences. 4(5): Pp. 319-323.

El-Nagger, N.; Ahmed, S.; Elsayed, L.; Khamis, H. (2013). Patients' Satisfaction Regarding Nursing Care Provided in Different Hospitals in Makkah AL Mukramah. Life Science Journal. 10(2).Pp 421-429

Fleischer, S.; Berg, A.; Zimmermann, M.; Wüste, K.; and Behrens, J. (2009). Nurse patient interaction and communication. Journal Public Health. 7(5):Pp.339-353.
Kuosmanen, L.; Hatonen, H.; Jyrkinen, A.; Katajisto, J.; and Valimaki, M. (2006). Patient satisfaction with psychiatric inpatient care. Journal of Advanced Nursing. 55(6).Pp.655-663.

Laschinger, H.; Hall, L.; Pedersen, C.; and Almost, J. (2005). A psychometric analysis of the patient satisfaction with nursing care quality questionnaire an actionable approach to measuring patient satisfaction. Journal of Nursing Care Quality. 20(3). P.p.220-230.

Mohsen A. (2004). Patients' needs, satisfaction, and health related quality of life. Towards a comprehensive model. Available on http://www.hqlo.com/content/2/1/32.

Papastavrou, E.; Andreou, P.; Tsangari, H.; and Merkouris, A. (2014). Linking patient satisfaction with nursing care: the case of care rationing - a correlational study. BMC Nursing. 13(26): Pp. 2-10.

Shnishil, A.; and Mansour, K. (2013). Assessment of Patients' Satisfaction toward Nursing Care at Hemodialysis units. Iraqi National Journal of Nursing Specialties. Vol. 26 (1):Pp.2-9.

Soufi, G.; Belayachi, J.; Himmich, S.; Ahid, S.; Soufi, M.; Zekraoui, A.; and Abouqal, R. (2010). Patient satisfaction in an acute medicine department in Morocco. BMC Health Services Research.10(149). P.p. 212

Tang, W.; Soong, C.; and Lim, W. (2013). Patient Satisfaction with Nursing Care: A Descriptive Study Using Interaction Model of Client Health Behavior. International Journal of Nursing Science. 3(2): P.p. 51-56.

Wagner, D.; and Bear, M. (2009). Patient satisfaction with nursing care: A concept analysis within a nursing framework. Journal of Advanced Nursing. 65(3). P.p. 692-701.

Ziaei, H.; Katibeh, M.; Eskandari, A.; Mirzadeh, M.; Rabbanikhah, Z.; and Javadi, M. (2011). Determinants of patient satisfaction with ophthalmic services. BMC Research. 4(7). P.p. 2-4. 